\title{
Concordance rate for Type II diabetes mellitus in monozygotic twins: actuarial analysis
}

\author{
F. Medici, M. Hawa, A. Ianari, D. A. Pyke, R.D.G Leslie \\ Department of Diabetes and Metabolism, St. Bartholomew's Hospital, London, United Kingdom
}

\begin{abstract}
Summary To determine the concordance rate for Type II (non-insulin-dependent) diabetes mellitus in monozygotic twin pairs, initially ascertained discordant for diabetes, we carried out a prospective study on 44 non-diabetic subjects, each of whom had a sibling twin with diabetes ( 21 men, 23 women, median age 55 years, interquartile range $47-65$ ). The subjects were referred as discordant for Type II diabetes. The twin pairs were part of the British Diabetic Twin Study and ascertained between May 1968 and January 1998. These subjects underwent an OGTT at time of referral and periodically thereafter. The mean follow-up was 8 years (range $0-18$ years) and data were collected until January 1996. The percentage of twins who developed Type II diabetes was assessed by stan-
\end{abstract}

dard actuarial life-table methods and the pairwise concordance rate, that is the proportion of concordant pairs over the sum of concordant and discordant pairs, was calculated. The observed rates of concordance for Type II diabetes at $1,5,10$, and 15 years follow-up were $17,33,57$, and $76 \%$, respectively. The concordance rate for any abnormality of glucose metabolism (either Type II diabetes or impaired glucose tolerance) at 15 years follow-up was $96 \%$. The concordance rate for Type II diabetes in monozygotic twins is very high even in twins initially ascertained discordant for diabetes. [Diabetologia (1999) 42: 146-150]

Keywords Type II diabetes mellitus, actuarial analysis, concordance rate, identical twins.
The pathogenesis of Type II (non-insulin-dependent) diabetes mellitus probably involves the interaction of genetic and environmental factors [1]. The nature of the genes which contribute to Type II diabetes in adults remains unclear. Genes have recently been identified which are associated with the development of Type II diabetes in children and young adults [2, 3].

Evidence that genetic factors are important in Type II diabetes derives largely from the study of twins and families; the risk in a sibling of a patient

Received: 16 March 1998 and in revised form: 26 August 1998

Corresponding author: R.D.G. Leslie M.D., FRCP, Department of Diabetes and Metabolism, St. Bartholomew's Hospital, Centre for Clinical Research, Dominion House, London EC1A 7BE, UK

Abbreviations: IGT, Impaired glucose tolerance; NGT, normal glucose tolerance; OGTT, oral glucose tolerance test. with the disease is about $10 \%$, higher than the risk in the general population, which is 1 to $3 \%[4,5]$. Such differences, however, could be due to shared environmental or genetic factors. Twins have been widely used to resolve the relative role of genetic and environmental factors. In the classic twin studies similarities (concordance) for a trait in identical and non-identical twin pairs are compared. A greater concordance rate in identical than non-identical twins suggests that genetic factors are important whilst similar concordance rates indicate a major role for environmental factors [5].

Early twin studies of patients with Type II diabetes indicated that the concordance rate between identical twins for Type II diabetes was very high (69 to $90 \%$ ) [5]. This observation was taken to establish a strong genetic basis for the disease and has been widely quoted as the basis for the intense current search for genes associated with Type II diabetes. These studies, however, were volunteer-based and cross-sectional 
with a high potential bias towards ascertaining concordant as against discordant pairs.

Type II diabetes, defined formally by a degree of oral glucose intolerance, has a peak incidence at the age of 50 years and a cumulative incidence that continues to increase into old age [4]. Thus, in any analysis of the frequency of Type II diabetes it is important to follow a cohort using oral glucose tolerance tests. There have been neither systematic prospective studies of Type II diabetic identical twins nor any using actuarial analysis. Actuarial analysis is designed to estimate event rates (in our case developing diabetes) in a cohort followed prospectively when both the duration of follow-up and number of cases under review varies during the study period. We therefore embarked on a prospective study of identical twins of Type II diabetes patients who were not diabetic at referral using actuarial analysis. The aim of the study was to determine whether the concordance rate in these identical twins was high and whether twins who remained non-diabetic had normal glucose tolerance.

\section{Subjects and methods}

As there is no twin register in Britain a systematic survey of all twins is not possible. The British Diabetic Twin Study includes data on identical twins, one or both of whom has diabetes, collected over 32 years. Twins in the study were ascertained because they were diabetic not because they were twins. To determine the lowest estimate of concordance for Type II diabetes, we selected identical twins in whom: 1 . the index twin had Type II diabetes; 2 . twin pairs were referred within 5 years of the diagnosis of the index twin; 3. the co-twin was not known to have diabetes at the time of referral; 4 . twin pairs were all of European origin, and 5. twins were ascertained between May 1968 and January 1998. Twins were then followed prospectively until either the end of the study or development of diabetes. By ascertaining twin pairs discordant for Type II diabetes, that is only one twin had the disease, we excluded some pairs in which both twins developed diabetes at a similar time. In this way we biased ascertainment and thus we are likely to have underestimated the true level of concordance.

Of our whole series of identical twins, 44 pairs fulfilled the criteria for selection and were studied ( 21 males, median age at diagnosis 55 years, interquartile range 47-65). Monozygosity was established as described previously [6], using 21 genetic markers to obtain a probability of monozygosity greater than $97 \%$. All but 3 of the 44 pairs were living apart at the start of the study. The non-diabetic twins were followed until 1 January 1998, when they had been observed for a mean of 8 years (range 0.1 to 18). Diabetes was diagnosed according to the $\mathrm{Na}-$ tional Diabetes Database Group Criteria [7]. All the non-diabetic twins underwent an oral glucose tolerance test (OGTT) when referred and periodically thereafter. Diabetes was diagnosed if fasting whole blood glucose was greater than $6.7 \mathrm{mmol} / \mathrm{l}$, or $2 \mathrm{~h}$ whole blood glucose greater than or equal to $10.0 \mathrm{mmol} / \mathrm{l}$ and one other intervening value greater than or equal to $10 \mathrm{mmol} / \mathrm{l}$ during OGTT. Impaired glucose tolerance (IGT) was defined as a whole blood glucose concentration between 6.7 and $10 \mathrm{mmol} / \mathrm{l}$ two hours after drinking glucose. OGTT was carried out until 1979 using a 50 g glucose load, a $75 \mathrm{~g}$ dose was used thereafter. These two different doses reflect the changes in the diagnostic criteria in 1979; it has been shown that doses of $50 \mathrm{~g}$ or $75 \mathrm{~g}$ given under standardised conditions, resulted in virtually identical blood glucose concentrations [7]. Before 197916 twin pairs were referred and 9 of them had their last follow up before that year.These 16 non-diabetic twins had an OGTT using $50 \mathrm{~g}$ instead of $75 \mathrm{~g}$ of glucose; we applied the same threshhold blood glucose concentrations to twins studied in the period before and after 1979. Whole blood glucose was measured using either potassium ferricyanide until 1979 or glucose oxidase method thereafter.

Those twins who were not tested every year were instructed to do urine glucose tests periodically and to report the presence of glycosuria or the onset of symptoms suggestive of hyperglycaemia to both their General Practioners and the investigators.

Statistical analysis. The twins were followed until the closing date or until they developed diabetes. The end-point of the study was the assessment of the pairwise concordance rate, that is the proportion of concordant pairs over the sum of concordant and discordant pairs. These data are expressed as a percentage (confidence interval). The percentage of twins who did not develop Type II diabetes was calculated by standard actuarial life-table methods [8]; the cumulative pairwise concordance rate being equal to 100 minus the probability of remaining non-diabetic twins expressed as a percentage. The standard error of a point estimate was computed using the Greenwood formula. Analysis was not done with less than five non-diabetic twins under study when any single event could have a major impact on disease-risk estimates.

Data on age at diagnosis of the index twin and age at last follow-up are expressed as means $\pm \mathrm{SD}$; sex is expressed as men/women ratio. Data on body mass index, lipid concentrations, blood pressure and macrovascular disease were not complete in all twins over the 16 years of study and were not analysed. Differences in age at diagnosis of the index twin, age at follow-up and sex of the twins who had normal glucose tolerance, IGT or diabetes at their last follow-up were assessed using analysis of variance (ANOVA) and Chi-squared for trend (GraphPad Instat Software V2.0.5 a, 950811B, GraphPad Software Inc., San Diego, Calif., USA).

\section{Results}

Of 44 identical twins referred to the study as non-diabetic, 22 developed diabetes and 13 were found to have IGT (Tables 1 and 2). Six of the subjects died during the follow-up period. All of the twins who became diabetic developed Type II diabetes. At referral OGTT disclosed frank diabetes in seven $(16 \%)$ and IGT in four $(9 \%)$ subjects. The observed rates of developing Type II diabetes at 1, 5, 10, and 15 years of follow-up were $17,33,57$, and $76 \%$, respectively. The median period between diagnosis of Type II diabetes in the first and second twin was 6 years (range 0.1-17 years). Details of actuarial analysis for the development of diabetes are reported in Table 1 and illustrated in Figure 1.

Details of the actuarial analysis of twins developing abnormal glucose metabolism (either Type II diabetes or IGT) are presented in Table 2 and summarised in Figure 2. The rates of concordance for abnor- 
Table 1. Actuarial analysis on the probability of developing Type II diabetes in monozygotic twin pairs initially discordant for the disease

\begin{tabular}{|c|c|c|c|c|c|c|}
\hline $\begin{array}{l}\text { Follow-up } \\
\text { (years) }\end{array}$ & $\begin{array}{l}\text { Number } \\
\text { at risk }\end{array}$ & $\begin{array}{l}\text { Type II } \\
\text { diabetes }\end{array}$ & $\begin{array}{l}\text { Lost from } \\
\text { follow-up }\end{array}$ & $\begin{array}{l}\text { Proportion } \\
\text { of subjects } \\
\text { remaining } \\
\text { non-diabetic }\end{array}$ & $\begin{array}{l}\text { Cumulative } \\
\text { probability } \\
\text { of remaining } \\
\text { non-diabetic }\end{array}$ & $\begin{array}{l}\text { Confidence } \\
\text { interval } \\
\text { of cumulative } \\
\text { probability }\end{array}$ \\
\hline $0-1$ & 44 & 7 & 7 & 0.827 & 0.827 & \\
\hline $1-2$ & 30 & 1 & 3 & 0.964 & 0.798 & $0.671-0.880$ \\
\hline $2-3$ & 26 & 1 & 0 & 0.961 & 0.767 & $0.633-0.857$ \\
\hline $3-4$ & 25 & 3 & 2 & 0.875 & 0.671 & $0.548-0.768$ \\
\hline $4-5$ & 20 & 0 & 0 & 1 & 0.671 & $0.501-0.794$ \\
\hline $5-6$ & 20 & 1 & 2 & 0.947 & 0.636 & $0.480-0.756$ \\
\hline $6-7$ & 17 & 2 & 2 & 0.875 & 0.556 & $0.413-0.678$ \\
\hline $7-8$ & 14 & 2 & 1 & 0.851 & 0.474 & $0.329-0.605$ \\
\hline $8-9$ & 11 & 0 & 1 & 1 & 0.474 & $0.295-0.633$ \\
\hline $9-10$ & 10 & 1 & 0 & 0.9 & 0.426 & $0.270-0.574$ \\
\hline $10-11$ & 9 & 0 & 0 & 1 & 0.426 & $0.247-0.594$ \\
\hline $11-12$ & 9 & 3 & 0 & 0.666 & 0.284 & $0.172-0.406$ \\
\hline $12-13$ & 6 & 0 & 0 & 1 & 0.284 & $0.126-0.465$ \\
\hline $13-14$ & 6 & 1 & 0 & 0.833 & 0.237 & $0.108-0.393$ \\
\hline $14-15$ & 5 & 0 & 0 & 1 & 0.237 & $0.093-0.417$ \\
\hline
\end{tabular}

${ }^{1}$ Lost from follow-up includes twins who either finished follow-up, did not wish to participate further, could no longer be located or died during the specified interval

Table 2. Actuarial analysis on the probability of developing glucose abnormalities (Type II diabetes or IGT) in monozygotic twin pairs initially discordant for Type II diabetes

\begin{tabular}{|c|c|c|c|c|c|c|}
\hline $\begin{array}{l}\text { Follow-up } \\
\text { (years) }\end{array}$ & $\begin{array}{l}\text { Number } \\
\text { at risk }\end{array}$ & $\begin{array}{l}\text { Type II } \\
\text { diabetes } \\
\text { or IGT }\end{array}$ & $\begin{array}{l}\text { Lost from } \\
\text { follow-up }\end{array}$ & $\begin{array}{l}\text { Proportion } \\
\text { of subjects } \\
\text { without Type II } \\
\text { diabetes or IGT }\end{array}$ & $\begin{array}{l}\text { Cumulative } \\
\text { probability of } \\
\text { not having } \\
\text { Type II diabetes } \\
\text { or IGT }\end{array}$ & $\begin{array}{l}\text { Confidence } \\
\text { interval } \\
\text { of cumulative } \\
\text { probability }\end{array}$ \\
\hline $0-1$ & 44 & 11 & 3 & 0.741 & 0.741 & \\
\hline $1-2$ & 30 & 4 & 0 & 0.866 & 0.642 & $0.521-0.740$ \\
\hline $2-3$ & 26 & 1 & 0 & 0.9611 & 0.617 & $0.466-0.737$ \\
\hline $3-4$ & 25 & 3 & 2 & 0.875 & 0.540 & $0.406-0.656$ \\
\hline $4-5$ & 20 & 0 & 0 & 1 & 0.540 & $0.382-0.674$ \\
\hline $5-6$ & 20 & 1 & 2 & 0.947 & 0.511 & $0.364-0.641$ \\
\hline $6-7$ & 17 & 3 & 1 & 0.818 & 0.418 & $0.295-0.537$ \\
\hline $7-8$ & 13 & 3 & 0 & 0.769 & 0.322 & $0.209-0.440$ \\
\hline $8-9$ & 10 & 2 & 0 & 0.8 & 0.257 & $0.146-0.384$ \\
\hline $9-10$ & 8 & 1 & 0 & 0.875 & 0.225 & $0.113-0.360$ \\
\hline $10-11$ & 7 & 0 & 0 & 11 & 0.225 & $0.104-0.375$ \\
\hline $11-12$ & 7 & 3 & 1 & 0.538 & 0.121 & $0.058-0.208$ \\
\hline $12-13$ & 3 & 0 & 0 & 1 & 0.121 & $0.039-0.251$ \\
\hline $13-14$ & 3 & 0 & 0 & 1 & 0.121 & $0.039-0.251$ \\
\hline $14-15$ & 3 & 3 & 0 & 0.0 & 0.040 & $0.014-0.083$ \\
\hline
\end{tabular}

${ }^{1}$ Lost from follow-up includes twins who either finished follow-up, did not wish to participate further, could no longer be located or died during the specified interval

mal glucose metabolism at $1,5,10$ and 15 years follow-up were $26,46,78$ and $96 \%$ respectively. At the end of the study, the majority (13/22) of the twins who remained non-diabetic had IGT.

There was no important difference in sex, age at diagnosis of the index twin or age at last follow-up among the twins who had normal glucose tolerance, IGT or diabetes at their last follow-up. Data is presented in Table 3 for sex, age of the index twin at diagnosis and age at last follow-up. There was no evidence that the rate of developing diabetes changed with time; thus, the rate of conversion to diabetes was not statistically different in each 5 year period up to 15 years after the diagnosis of the index twin (that is 33,24 and $19 \%$ respectively).

\section{Discussion}

This prospective study of a cohort of 44 identical twins of Type II diabetic patients, who were not known to have diabetes themselves on referral, showed a rate of development of Type II diabetes after 15 years follow-up of $76 \%$. Of those twins who re- 


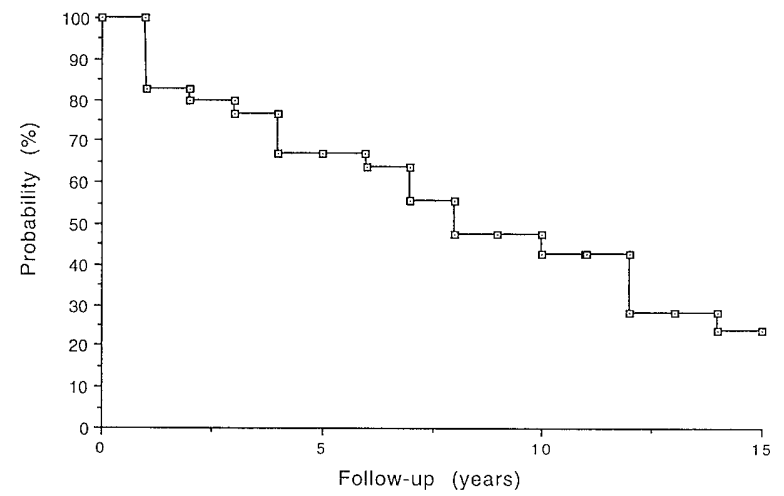

Fig. 1. Cumulative probability of remaining non-diabetic

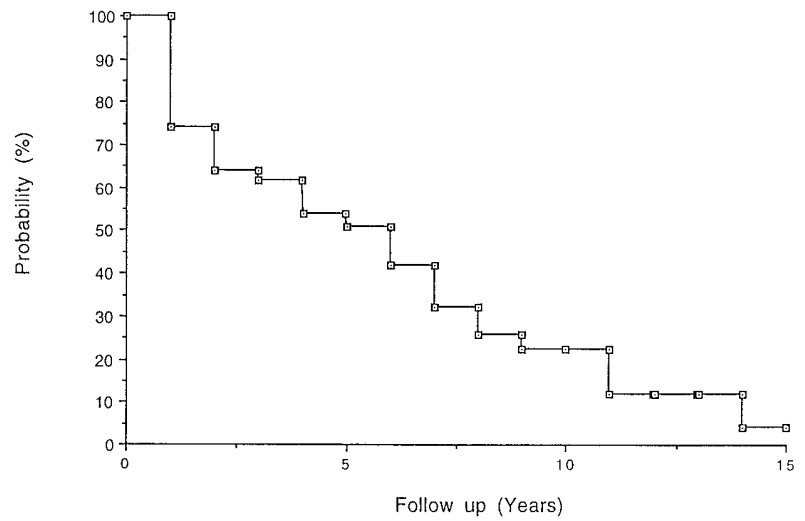

Fig. 2. Cumulative probability of remaining neither diabetic nor having IGT

mained non-diabetic at the end of the study, the majority had IGT. While it is possible that these twins will remain non-diabetic, analysis of the rates of developing diabetes in the twins suggested that there was no decline in the conversion rate by the end of the study and, therefore, that the concordance rate for Type II diabetes in the twins we studied will become higher. These observations indicate that Type II diabetes is likely to develop in a subject genetically susceptible to the disease.

Our study was limited to identical twins. To estimate whether a high concordance rate in identical twins reflects a strong genetic effect it is necessary to compare the concordance rate in identical and nonidentical twins. We have not done this and it will be some time before we will have studied enough nonidentical pairs over a sufficiently long period to reach a firm conclusion. Our ascertainment of identical twins for this study was deliberately biased to only include twins referred discordant for Type II diabetes, thus probably underestimating the true concordance rate. Ascertainment was not population-based but by referral to the study. Only 44 twin pairs were studied. Moreover, we followed twins from time of referral for a mean of only 8 years and the majority of those who remained non-diabetic might yet develop diabetes
Table 3. Characteristics of twins at their last follow-up or when diagnosed with Type II diabetes

\begin{tabular}{llll}
\hline & NGT $(n=9)$ & IGT $(n=13)$ & $\begin{array}{l}\text { Type II } \\
\text { diabetes } \\
(n=22)\end{array}$ \\
\hline $\begin{array}{l}\text { Age at diagnosis } \\
\text { of index twin (years) }\end{array}$ & $54.7 \pm 19.3$ & $51.8 \pm 15.1$ & $50.1 \pm 12.8$ \\
$\begin{array}{l}\text { Age at last follow-up } \\
\text { (years) }\end{array}$ & $59.2 \pm 19.8$ & $57.8 \pm 15.9$ & $57.9 \pm 12.9$ \\
Sex (men/women) & $4 / 5$ & $6 / 7$ & $11 / 11$ \\
\hline
\end{tabular}

There was no significant difference between the three groups for any of the three parameters. Data are mean \pm SD

since they already had IGT. There was no decline in the rate of twins developing diabetes by the end of the study and four of the eight non-diabetic twins, who had glucose tolerance tests after they developed IGT, subsequently developed Type II diabetes. Despite the biases in this study which could have led to an underestimation of the true concordance rate, the concordance rate for Type II diabetes was high.

Cross-sectional twin studies of the heritability of disease are flawed if the disease incidence increases with age and if ascertainment is through physicianbased referral. Nevertheless, such studies of Type II diabetic twins have been widely cited to support a high concordance in identical twins [9-11]. One of these earlier studies was our own which showed a pairwise concordance rate in Type II diabetic identical twins of about $90 \%$ [9]. Two other cross-sectional studies of twins in the USA and Japan, ascertained through physician-based referral, showed a higher pairwise concordance rate in identical (69 and $83 \%$ ) than non-identical (24 and $40 \%$ respectively) pairs $[10,11]$. In the American study the non-diabetic twins did not have glucose tolerance tests to check for diabetes [10]. Testing twins to exclude diabetes is essential as Type II diabetes could be present, but undiagnosed. In this study $16 \%$ of twins at referral were only found to have diabetes after a glucose tolerance test.

There have been two cross-sectional populationbased twin studies of Type II diabetes, one from the USA and the other from Finland $[12,13]$. The non-diabetic twins were not consistently tested in either study. The American study relied on self-reporting of diabetes while the Finnish study identified twins only through prescriptions for antidiabetic drugs which excluded all patients treated by diet alone. Nevertheless, both studies reported a genetic effect determining the disease. In the Finnish study the pairwise concordance rate was higher for identical $(20.4 \%)$ than non-identical $(8.8 \%)$ twin pairs [12]. The American study highlighted the problem of cross-sectional studies in that initially the pairwise concordance rate for Type II diabetes was slightly higher in identical $(16.7 \%)$ than in non-identical $(7.7 \%)$ pairs; however, on repeat testing, approximately 10 years after the 
first test, the concordance rate in identical twins was substantially higher $(41.2 \%)$ than in the non-identical twins $(9.5 \%)$ [13]. The rate of diabetes in the American study was probably underestimated owing to firstly, their unconventional definition of diabetes: a blood glucose greater than $13.9 \mathrm{mmol} / \mathrm{l} 1 \mathrm{~h}$ after a 50 g glucose oral load (conventional criteria would have given $65 \%$ concordance), and secondly, actuarial analysis was not done.

Genes determining susceptibility to Type II diabetes could influence insulin secretion or insulin sensitivity in predisposing to the disease, or both. The limited number of metabolic studies in non-diabetic twins of Type II diabetic patients tend to be insulin resistant with delayed insulin secretory capacity to both oral and intravenous glucose [14-16]. Studies in normal twins have shown that a substantial fraction of the variability in blood glucose concentrations, both when fasting and following an oral glucose load, can be attributed to genetic influences, however it remains unclear to what extent the metabolic changes in Type II diabetes are genetically determined [17].

Environmental factors are likely to be important in causing Type II diabetes as concordance falls short of $100 \%$ and twins differ in rates of progression to the disease. Twin studies, however, have had limited success in identifying such factors. Birth weight, physical fitness and adult weight gain have been implicated in disease risk [18-20]. Identical twins are more likely than non-identical twins to have intrauterine malnutrition. While low birth weight could be due to abnormal glucose tolerance, it did not lead to differences in glucose metabolism between identical and non-identical twins [18]. Physical fitness is also related to glucose metabolism and has been implicated as a factor in determining the risk of developing Type II diabetes [19]. Finally, adult weight gain has been found to be greater in both Type II diabetic twins and their nondiabetic twins than in control twins; thus, adult weight gain, which has been associated with an increased risk of diabetes, may be genetically determined [12, 20].

We conclude that the great majority of identical twin pairs are likely to become concordant for Type II diabetes or IGT. While environmental factors might play a role in the development of diabetes, genetic factors are important. We cannot be certain that Type II diabetes is largely genetically determined but our study shows that subjects genetically susceptible to Type II diabetes are very likely to develop the disease.

Acknowledgements. This study was supported by the Diabetic Twin Research Trust and the British Diabetic Association. We are indebted to the twins and physicians who made these studies possible.

\section{References}

1. Polonsky KS, Sturis J, Bell GIB (1996) Non-insulin dependent diabetes mellitus - a genetically programmed failure of the beta cell to compensate for insulin resistance. $\mathrm{N}$ Engl J Med 334: 777-783

2. Yamagata K, Oda N, Kaisaki PJ et al. (1996) Mutations in the hepatocyte nuclear factor-1 alfa gene in maturity-onset diabetes of the young (MODY3). Nature 384: 455-458

3. Yamagata K, Furuta H, Oda N et al. (1996) Mutations in the hepatocyte nuclear factor-4 alfal gene in maturity-onset diabetes of the young (MODY1). Nature 384: 458-460

4. Amos AF, McCarthy DJ, Zimmet P (1997) The rising global burden of diabetes and its complications: estimates and projections to the year 2010. Diabet Med 14 [Suppl 5]: S1-S85

5. Lo SSS, Tun RYM, Hawa M, Leslie RDG (1991) Studies of diabetic twins. Diabetes/Metabolism Reviews 7: 223-238

6. Cederloff R, Friberg L, Jonsson E, Kaij L (1961) Studies of similarity diagnosis in twins with the aid of mailed questionnaires. Acta Genet Statist Med 11: 338-362

7. National Diabetes Data Group (1979) Classification and diagnosis of diabetes mellitus and other categories of glucose intolerance. Diabetes 28: 1039-1057

8. Elandt-Johnson RL, Johnson NL (1980) Survival models and data analysis. John Wiley and Sons, New York

9. Barnett AH, Eff C, Leslie RDG, Pyke DA (1981) Diabetes in identical twins: a study of 200 pairs. Diabetologia 20: 87-93

10. Gottlieb MS, Root HF (1968) Diabetes mellitus in twins. Diabetes 17: 693-704

11. Committee on Diabetic Twins, Japan Diabetes Study (1988) Diabetes mellitus in twins: a cooperative study in Japan. Diabetes Res Clin Pract 5: 271-280

12. Newman B, Selby JV, King MC, Slemenda C, Fabsitz R, Friedman GD (1987) Concordance for Type 2 (non-insulin dependent) diabetes mellitus in male twins. Diabetologia 30: 763-768

13. Kaprio J, Tuomilehto J, Koskenvuo M et al. (1992) Concordance for Type 1 (insulin dependent) and Type 2 (non-insulin dependent) diabetes mellitus in a population-based cohort of twins in Finland. Diabetologia 35: 1060-1067

14. Barnett AH, Sipiliopoulos AJ, Pyke DA et al. (1981) Metabolic studies in unaffected co-twins of non-insulin dependent diabetics. BMJ 282: 1656-1658

15. Vaag A, Henriksen JE, Madsbad S, Holm N, Beck-Nielsen H (1995) Insulin secretion, insulin action, and hepatic glucose production in identical twins discordant for non-insulin dependent diabetes mellitus. J Clin Invest 95: 690-698

16. Selby JV, Newman B, Quesenberry et al. (1987) Genetic and behavioural influences on body fat distribution. Int $\mathbf{J}$ Obesity 125: 979-988

17. Poulsen P, Vaag AA, Kyvik KO, Moller Jensen D, BeckNielsen H (1997) Low birth weight is associated with NID$\mathrm{DM}$ in discordant monozygotic and dizygotic twin pairs. Diabetologia 40: 439-446

18. Manson JE, Rimm EB, Stampfer JJ et al. (1991) Physical activity and incidence of non-insulin dependent diabetes mellitus in women. Lancet 338: 774-778

19. Helmrich SP, Ragland DR, Leung RQ, Paffemberg RS (1991) Physical activity and reduced occurrence of non-insulin dependent diabetes mellitus. N Engl J Med 325: $147-152$

20. Colditz GA, Willett WC, Stampfer MJ et al.(1990) Weight as a risk factor for clinical diabetes in women. Am J Epidemiol 132: 501-513 